
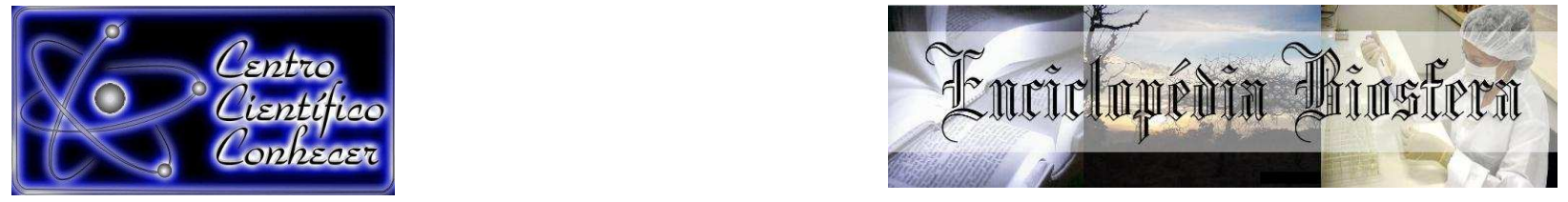

\title{
CARDIOTOXICIDADE INDUZIDA PELA DOXORRUBICINA: PATOGENIA, DIAGNÓSTICO E TERAPIAS ANTIOXIDANTES
}

\author{
Léa Resende Moura ${ }^{1}$; Ângela Alves Viegas ${ }^{2}$; Priscilla Regina Nasciutti ${ }^{1}$; Rosângela \\ de Oliveira Alves Carvalho ${ }^{3}$; Veridiana Maria Brianezi Dignani de Moura ${ }^{3}$ \\ ${ }^{1}$ Doutoranda, Programa de Pós-Graduação em Ciência Animal, área de Patologia, \\ Clínica e Cirurgia animal, Universidade Federal de Goiás, Goiânia, Goiás, Brasil \\ ${ }^{2}$ Mestre, docente, Curso de Medicina, UniEvangélica, Anápolis, Goiás, Brasil \\ ${ }^{3}$ Doutora, docente, Escola de Veterinária e Zootecnia, Universidade Federal de \\ Goiás (UFG), Goiânia, Goiás, Brasil \\ (email para correspondência: lea vet@hotmail.com)
}
Recebido em: 08/09/2015 - Aprovado em: 14/11/2015 - Publicado em: 01/12/2015 DOI: http://dx.doi.org/10.18677/Enciclopedia Biosfera 2015 113

\begin{abstract}
RESUMO
A doxorrubicina (DOX) é um antibiótico da família das antraciclinas (ANT) e se destaca como um dos mais importantes antitumorais utilizados na medicina e medicina veterinária. Possui valor clínico limitado pela cardiotoxicidade, associada à sua concentração sérica. A cardiotoxicidade induzida por ANT é frequente em pacientes submetidos a doses acima de $500 \mathrm{mg} / \mathrm{m}^{2}$ e atribuída à lipoperoxidação das membranas dos cardiomiócitos. Dentre os exames para o monitoramento cardíaco antes, durante e após a quimioterapia com ANT, os mais utilizados são os de imagem e marcadores bioquímicos. A radiografia é um exame simples e o primeiro a ser realizado. Porém, possui limitação diagnóstica por avaliar apenas a cardiomegalia. Por outro lado, a eletrocardiografia é extremamente útil nos quadros agudos de cardiotoxicidade induzida pela DOX, em que as arritmias são comuns. A ecocardiografia compreende o método mais utilizado por ser pouco invasivo e de amplo valor diagnóstico. Já a biópsia miocárdica é um método diagnóstico efetivo, porém invasivo, o que limita sua aplicação. A DOX é uma dentre várias fontes exógenas de radicais livres. Nesse contexto, substâncias naturais como fenois, flavonoides, tocoferois, ácido ascórbico, carotenoides e vitamina $E$ representam compostos químicos com atividade antioxidante e têm sido alvo de investigação científica com o objetivo de reduzir a cardiotoxidade induzida pela DOX sem diminuir seu potencial quimioterápico.
\end{abstract}

PALAVRAS-CHAVE: Antraciclina, estresse oxidativo, cardiomiopatia dilatada, ecocardiografia, histopatologia.

\section{CARDIOTOXICITY INDUCED BY DOXORUBICIN: PATHOGENESIS, DIAGNOSIS AND THERAPY WITH ANTIOXIDANTS}

\begin{abstract}
The doxorubicin (DOX) is an antibiotic of anthracyclines family (ANT) which stands out as one of the most important antitumoral used in human and animals. It has limited clinical value due to its cardiotoxicity, which is associated with its serum concentration. The cardiotoxicity of ANT is common in pacients receiving doses


above $500 \mathrm{mg} / \mathrm{m}^{2}$ and it is attributed to lipid peroxidation of cardiomyocytes membranes. Among the tests for cardiac monitoring before, during and after chemotherapy with ANT the most used are the imaging and biochemical markers. Radiography is a simple test and the first to be performed. However, it has diagnostic limitation for assessing only the cardiomegaly. Moreover, electrocardiography is very useful to acute cases of cardiotoxicity induced by the DOX in which arrhythmias are common. The echocardiography is the most widely used method because it is minimally invasive and has extensive diagnostic value. Myocardial biopsy is an effective diagnostic method, however invasive, which limits its application. The DOX is one of several exogenous sources of free radicals. In this context, natural substances such as phenols, flavonoids, tocopherols, ascorbic acid, carotenoids, and vitamin $\mathrm{E}$ represent chemicals with antioxidant activity and have been investigated with the objective of reducing cardiotoxicity induced by DOX without decrease its chemotherapeutic potential.

KEYWORDS: Anthracycline, oxidative stress, dilated cardiomyopathy, ecocardiography, histopathology.

\section{INTRODUÇÃO}

As antraciclinas (ANT) são antibióticos citostáticos que exercem ação através da inibição da topoisomerase II (MENNA et al., 2012). Os fármacos mais representativos desse grupo são a doxorrubicina (DOX), ativa contra cânceres hematológicos e sólidos (AEBI et al., 2011), e a daunorrubicina, utilizada principalmente no câncer hematológico agudo. Também fazem parte do grupo das ANT os fármacos epirrubicina, idarrubicina e mitoxantrona (CREUTZIG et al., 2012).

A DOX foi isolada de culturas de Streptomyces peucetius, variante caesius, e tem sido utilizada na prática oncológica desde a década de 1960. A identificação de seu alvo, assim como das ANT, foi um marco importante na farmacologia das substâncias anticâncer (YANG et al., 2014). A regressão tumoral é expressiva no uso isolado da DOX e significativamente maior quando combinada a outros agentes antitumorais. Apesar disso, sua utilidade clínica é limitada devido a seu potencial cardiotóxico e possibilidade de desenvolvimento de resistência à droga (BARRETT-LEE et al., 2009).

Historicamente duas descobertas sobre a DOX foram importantes para os cardiologistas. Primeiro, que a cardiotoxicidade relaciona-se à dose cumulativa e, segundo, que mudanças estruturais características em miócitos ocorrem e podem ser quantificadas por microscopia eletrônica (BILLINGHAM et al., 1978). A cardiomiopatia induzida por ANT dependente da dose foi descrita pela primeira vez em 1971, em tratados com adriamicina contra uma variedade de tumores (MIDDLEMAN et al., 1971). Mais tarde, em 1984, foram evidenciados os efeitos da cardiotoxicidade com o reconhecimento de alterações ultraestruturais observadas em material de biopsia cardíaca. Até então a importância dos efeitos cardiotóxicos da DOX não eram reconhecidos. Quase uma década depois, mais uma evidência de morte celular foi constatada pela elevação dos níveis séricos de troponina I cardíaca, e pela demonstração da relação matemática entre doses cumulativas de DOX em função da probabilidade da ocorrência de insuficiência cardíaca congestiva (CARDINALE et al., 2002; EWER \& BENJAMIN, 2005).

A cardiotoxicidade induzida por quimioterápicos é classificada de acordo com o dano celular produzido. A cardiotoxicidade tipo I implica em morte celular por necrose ou apoptose, sendo, portanto, irreversível. Na cardiotoxicidade tipo II ocorre apenas disfunção celular, sendo então considerada reversível. As ANT e os 
anticorpos monoclonais, como o trastuzumabe, promovem lesões irreversíveis e reversíveis, respectivamente (ESCHENHAGEN et al., 2011).

Nos dias de hoje, mesmo com o uso de protocolos com baixas doses e regimes cardioprotetores disponíveis, a cardiotoxicidade pela DOX ainda ocorre, e a prevenção continua a ser 0 objetivo de cardiologistas e oncologistas. A cardiotoxicidade das ANT é progressivamente frequente com doses acima de 500 $\mathrm{mg} / \mathrm{m}^{2}$ e atribuída principalmente à lipoperoxidação das membranas dos cardiomiócitos (SCHOEN \& MITCHELL, 2010). A incidência de insuficiência cardíaca é de aproximadamente $2 \%$ com a dose cumulativa de $300 \mathrm{mg} / \mathrm{m}^{2}$, aumentando rapidamente para $20 \%$ mediante doses cumulativas de $550 \mathrm{mg} / \mathrm{m}^{2}$ (JAIN, 2000).

A avaliação cardíaca antes, durante e após o tratamento quimioterápico é controversa. Não há evidência que determine qual o acompanhamento necessário. Alguns algoritmos propostos para a triagem de pacientes antes do tratamento e para avaliar a função cardíaca durante e após a terapia não possuem dados que demonstrem vantagem de um programa de monitoramento em detrimento de outro. Ainda, esses modelos avaliam apenas o risco cardíaco, sem esclarecer quanto ao benefício da terapia oncológica, que varia entre os tipos tumorais (EWER et al., 2007; JONES et al., 2009).

Apesar dos esforços investigativos, o mecanismo de cardiotoxicidade induzida pela DOX continua mal compreendido e, consequentemente, as formas de prevenção e controle são limitadas (EWER \& EWER, 2010). Considerando o uso frequente da DOX como quimioterápico na medicina e medicina veterinária, bem como o efeito cardiotóxico desse fármaco, esta revisão tem como objetivo reunir informações acerca da patogenia, dos métodos diagnósticos para lesões induzidas pela DOX e das terapias antioxidantes utilizadas.

\section{REVISÃO DE LITERATURA}

\section{Patogenia da cardiotoxicidade induzida pela DOX}

A cardiotoxicidade induzida pela DOX é classificada cronologicamente em aguda, subaguda, crônica e tardia, de acordo com o tempo decorrido entre a administração do fármaco e o início dos sintomas de toxicidade. A forma aguda ocorre durante ou imediatamente após a administração da droga, principalmente quando aplicada em velocidade rápida, e envolve vasodilatação, hipotensão e arritmias. A subaguda é incomum e se manifesta dias após o término da quimioterapia, seguida de pericardite e/ou miocardite. A forma crônica, que recebe mais atenção e tem sido amplamente estudada, se desenvolve semanas ou meses após o término do tratamento. Esta caracteriza-se por cardiomiopatia dilatada (CMD), com desenvolvimento subsequente de disfunção contrátil e insuficiência cardíaca (IC) em 4-23\% dos pacientes, dependendo do regime de tratamento, da idade, dose cumulativa, suscetibilidade individual ou histórico médico de hipertensão e doença cardíaca coronária. A forma tardia se assemelha à crônica, podendo ocorrer anos após o término do tratamento (ŠTĚRBA et al., 2012; SALAZARMENDIGUCHÍA et al., 2014; POLEGATO et al., 2015).

O conhecimento sobre a cardiotoxicidade induzida por ANT decorre principalmente de análises retrospectivas de pacientes com câncer que têm insuficiência cardíaca sintomática durante ou após a quimioterapia. Isso leva a grandes variações na estimativa de incidência e prognóstico dessa cardiotoxicidade e tem contribuído para a falta de diretrizes reconhecidas para a vigilância e gestão dessa importante complicação da terapia do câncer (GROARKE \& NOHRIA, 2015). 
Atualmente, a cardiotoxicidade da DOX é tão bem estabelecida que a droga vem sendo empregada em modelos experimentais utilizados para fins de pesquisa sobre a CMD em humanos e animais (PONTES et al., 2010). Na cardiomiopatia induzida pela DOX ocorre disfunção contrátil do músculo cardíaco, gerando incapacidade do coração em bombear sangue e, consequentemente, oxigênio na quantidade ideal para atender as necessidades do metabolismo celular (SCHOEN \& MITCHELL, 2010).

A DOX possui elevada afinidade pelo núcleo das células, onde se localizam $60 \%$ do quimioterápico intracelular. Para alcançar o objetivo como quimioterápico, as ANT se intercalam com o DNA, causando ruptura dos filamentos único e duplo, bem como troca de cromátides irmãs, impedindo a multiplicação celular. Similar a outros fármacos intercalantes de DNA, a DOX possui ação inibidora sobre a topoisomerase II, uma enzima importante no processo de replicação do DNA. Em função desses mecanismos, as ANT podem ser mutagênicas e carcinogênicas (FORREST et al., 2012).

Graças a seu grupo quinona, as ANT também geram radicais livres ( $R L)$ em tecidos normais e malignos. Para isso, reagem com a citocromo $P 450$ redutase na presença de NADPH, formando intermediários de radicais semiquinonas. Estes, por sua vez, reagem com o oxigênio catabolizado pelo ferro (reação de Fenton), produzindo radicais de ânion superóxido, que gera peróxido de hidrogênio e radicais hidroxila (LUBIENIECKA et al., 2013; GAMMELLA et al., 2014).

Há várias hipóteses para explicar a cardiotoxicidade pelas ANT, sendo a formação de RL a mais aceita. De acordo com ŠIMU゚NEK et al., (2009), têm sido sugeridas propostas para explicar o motivo pelo qual o coração é o principal alvo de toxicidade das ANT. Um composto denominado cardiolipina, presente no interior das mitocôndrias, exerce poder atrativo às ANT (MONTEIRO et al., 2013). Uma teoria sugere que a abundância de mitocôndrias nesse tecido pode aumentar significativamente a produção de metabólitos derivados do oxigênio, que em conjunto são chamadas espécies reativas de oxigênio (ERO). Outra, que os níveis das enzimas catalase e glutation peroxidase são menores no tecido cardíaco, reduzindo a atividade antioxidante endógena (NOEMAN et al., 2011). Sugere-se ainda maior retenção das ANT no tecido cardíaco (ŠIMU゚NEK et al., 2009).

Evidências sugerem outros mecanismos envolvidos no processo, estes possivelmente associados ao estresse oxidativo (GRANADOS-PRINCIPAL et al., 2010). Sabe-se que a DOX desencadeia a liberação de mediadores químicos inflamatórios, metabólitos do ácido araquidônico e citocinas pró-inflamatórias, como TNF- $\alpha$ e IL-6, que podem favorecer a progressão das lesões nos miócitos (GUO et al., 2013). Além desses mecanismos, o influxo de cálcio, o distúrbio da função adrenérgica do miocárdio e a interação com o sistema contrátil actina-miosina também foram propostos. Tais alterações geram danos intracelulares ou morte dos cardiomiócitos, resultando em futura fibrose miocárdica (GÖRLACH et al., 2006).

Outro mecanismo atualmente considerado importante na cardiotoxicidade pela DOX é a apoptose, que resulta em ativação de proteases e ocorre por diferentes rotas. As mais comuns compreendem a ativação de caspases por via direta, via alteração mitocondrial e por interferência de proteínas citoplasmáticas reguladoras da apoptose. Substâncias químicas como a DOX podem atingir o genoma da célula e ativar a expressão do gene P53 e seu produto, a proteína p53, induzindo retardo mitótico e apoptose. Um dos principais alvos da p53 são os genes das proteínas inibidoras da apoptose (IAP). Assim, as caspases naturalmente inibidas pelas IAP tornam-se ativas. Além disso, a p53 ativa os genes das proteínas 
pró-apoptóticas Bax (proteína $X$ associada ao Bcl-2), que se dimerizam com as proteínas antiapoptóticas Bcl-2 (proteínas reguladoras da apoptose), resultando em aumento da permeabilidade mitocondrial, com liberação de fatores pró-apoptóticos (CARVALHO et al., 2014).

Estudos recentes têm sugerido um novo mecanismo subjacente da cardiotoxicidade pela DOX, a ativação do sistema ubiquitina-proteassoma (UPS), esta induzida pela dose terapêutica de DOX, gerando proteólise e degradação de fatores de transcrição cardíacos e de proteínas reguladoras de cardiomiócitos. 0 UPS promove a degradação específica da maioria das proteínas celulares, além de cumprir funções não proteolíticas importantes na célula. Notavelmente, estudos experimentais recentes sugerem que a ativação do proteassoma promove remodelamento cardíaco durante a hipertensão. Além disso, a inibição do proteosoma tem sido clinicamente utilizada para tratar certos tipos de câncer e a disfunção do proteassoma é cada vez mais associada à disfunção cardíaca (RANEK \& WANG, 2010; ZHAO et al., 2015).

A constatação de que a DOX pode vincular-se ao proteassoma na célula antes da translocação para o núcleo levantou a possibilidade de que a mesma pode alterar a função do proteassoma. Entretanto, o mecanismo pelo qual a DOX ativa o proteassoma ainda não foi esclarecido. Evidências experimentais diretas e indiretas sugerem que DOX ativa o UPS em cardiomiócitos in vivo e in vitro, mas se isso ocorre em seres humanos, especialmente em pacientes com câncer tratados com DOX, necessita ser investigado, assim como a contribuição da ativação do UPS na cardiotoxicidade aguda e crônica induzidas por DOX (RANEK \& WANG, 2010).

\section{Métodos de diagnóstico na detecção da cardiotoxicidade induzida pela DOX}

Embora a necessidade de monitoramento cardíaco de pacientes assintomáticos tratados com ANT seja reconhecida, a decisão clínica em cardiooncologia é frequentemente limitada pela escassez de estudos prospectivos de longo prazo e de diretrizes robustas baseadas em evidências. O painel de especialistas em sobrevivência em câncer da Sociedade Americana de Oncologia Clínica considera insuficientes as evidências encontradas em revisões sistemáticas da literatura para orientar práticas clínicas na triagem de efeitos cardíacos induzidos por quimio ou radioterapia (CARVER et al., 2007). Como tal, as orientações disponíveis são baseadas em consenso ao invéz de evidência, e diferenças entre as diretrizes têm dificultado a implementação efetiva das recomendações. Isso contribui para a significativa variação de medidas de vigilância e controle da cardiotoxicidade por ANT (EARLE, 2007; ARMENIAN et al., 2015).

Dentre os exames disponíveis para o diagnóstico e monitoramento de alterações cardíacas antes, durante e após a quimioterapia com ANT, os mais utilizados são os exames de imagem e marcadores bioquímicos.

\section{- Avaliação radiográfica do tórax}

A análise radiográfica é um método sensível em determinar as dimensões das câmaras cardíacas no processo de monitoramento das cardiomiopatias induzidas pela DOX. Para a realização desse exame, incidências torácicas laterais e dorsoventrais ou ventrodorsais fornecem informações valiosas acerca das condições do coração e dos grandes vasos. Para as incidências dorsoventrais ou ventrodorsais o tórax inteiro deve estar sobre o filme. O posicionamento simétrico e a centralização do feixe de raios- $X$ são essenciais para a obtenção de imagens de boa qualidade. $A$ rotação pode causar distorções significativas na aparência do coração e estruturas 
adjacentes. As radiografias devem ser realizadas no momento da inspiração para evitar variações na aparência da silhueta cardíaca (GRAHAM et al., 2012).

Em cães, para mensurar o tamanho do coração pode ser utilizado o sistema de unidade vertebral, em que se comparam os comprimentos das vértebras torácicas às dimensões cardíacas. Dessa forma, determina-se o tamanho do coração em relação à unidade de vértebra torácica, método denominado VHS [do inglês vertebral heart size] (CARDOSO et al., 2011). Os valores do VHS devem ser inferiores a 10,5 vértebras para a maioria das raças, podendo haver variações de até 11 vértebras para raças de tórax curto e até 9,5 vértebras para aquelas de tórax longo (SLEEPER \& BUCHANAN, 2001).

Um estudo avaliou 30 cães adultos clinicamente saudáveis da raça Bulldog Inglês, com o objetivo de estabelecer parâmetros ecodopplercardiográficos, eletrocardiográficos, radiográficos e morfométricos de normalidade para a raça. $O$ valor de VHS encontrado foi de até 12 vértebras, o que reafirma a possibilidade de variações raciais nesses índices, especialmente relacionadas à conformação do tórax (BASILE, 2008).

Apesar de o exame radiográfico ser amplamente utilizado na medicina veterinária, este não vem sendo incluído nos trabalhos experimentais que avaliam as lesões induzidas pela DOX. De outra parte, na rotina clínica médico veterinária, em pacientes com suspeita de doença cardíaca, incluindo aquelas decorrentes da administração de ANT, muitas vezes esse é o primeiro exame a ser realizado e, a partir dos resultados, são indicados testes específicos como a eletrocardiografia e ecocardiografia. Entretanto, o uso da ragiografia no diagnóstico precoce de doenças cardíacas decorrentes de terapia anticâncer não é recomendado devido à baixa sensibilidade do exame no referido período da enfermidade (WALKER et al., 2013).

\section{- Avaliação eletrocardiográfica}

A eletrocardiografia compreende o método de diagnóstico mais importante das arritmias cardíacas, podendo determinar o ritmo e a frequência do coração. Também auxilia na determinação do tipo, da origem e severidade das arritmias, permitindo o direcionamento do protocolo terapêutico (FILIPPI, 2011). As arritmias são relatadas na cardiotoxicidade aguda pela DOX. Embora a maioria dos pacientes permaneça assintomática durante e após a infusão do fármaco, a lesão miocárdica pode iniciar imediatamente após a infusão (KITTIWARAWUT et al., 2013; POLEGATO et al., 2015). Por essa razão, anormalidades eletrocardiográficas podem ser detectadas, principalmente QRS de baixa voltagem, prolongamento do intervalo QT, alterações no segmento ST, inversão da onda T, taquicardia sinusal, ventricular ou supraventricular, bloqueio atrioventricular e bloqueio de ramos (OLIVEIRA, 2006; POLEGATO et al., 2015). Essas alterações são encontradas em aproximadamente $11 \%$ dos pacientes (SHI et al., 2011). As arritmias são geralmente transitórias, mas há casos de taquicardia ventricular que pode evoluir para insuficiência cardíaca crônica ou morte súbita (LARSEN et al., 1992). Entretanto, nos protocolos quimioterápicos os pacientes não são comumente monitorados por eletrocardiografia durante ou após o tratamento (OLIVEIRA, 2006).

Anormalidades eletrocardiográficas não ocorrem somente na fase aguda do tratamento com ANT. Indivíduos que sobrevivem às neoplasias podem apresentar arritmias em fases tardias, mesmo recebendo doses acumuladas de ANT inferiores a $300 \mathrm{mg} / \mathrm{m}^{2}$ (OLIVEIRA 2006; CURIGLIANO et al., 2012). LARSEN et al. (1992) sugeriram que a eletrocardiografia dinâmica ambulatorial, realizada pelo sistema Holter em 24 horas, deve ser inserida como método de monitoramento 
cardíaco na cardiotoxicidade tardia induzida pela DOX. Isso juntamente com a ecocardiografia pelo fato da eletrocardiografia não fornecer informações acuradas sobre o tamanho do coração e o aumento das câmaras. Além da ecocardiografia, as radiografias torácicas também podem ser realizadas para a avaliação do aumento das câmaras cardíacas (FILIPPI, 2011).

Para os experimentos de curta duração, em que as lesões de fase aguda são esperadas, é comum a utilização de eletrocardiografia associada a exames bioquímicos. OZDOĞAN et al. (2011) testaram o efeito protetor da carnosina, um dipeptídeo, na neutralização de RL em lesões induzidas pelas ANT. Os autores notaram efeitos positivos revelados pela normalização da eletrocardiografia e dos níveis enzimáticos. De forma semelhante, SANTOS et al. (2009) avaliaram anormalidades eletrocardiográficas e ecocardiográficas em pacientes após o uso de DOX. Houve modificações eletrocardiográficas em $100 \%$ dos pacientes que apresentaram redução da fração de ejeção do ventrículo esquerdo (FEVE), onde a alteração da repolarização ventricular foi a mais frequente. A mudança no eletrocardiograma (ECG) apresentou valores de sensibilidade de $100 \%$, especificidade de $100 \%$ e acurácia de $95 \%$. Por se tratar de um método não invasivo, de baixo custo e fácil realização para os cardiologistas, o ECG pode ser utilizado para rastrear pacientes que necessitam de avaliação por métodos de cardioimagem. Segundo os mesmos autores, não foram encontradas nas sociedades internacionais de cardiologia e oncologia diretrizes sobre as medidas ideais de diagnóstico de IC decorrente da ação de quimioterápicos.

\section{- Avaliação ecodopplercardiográfica}

A detecção de alterações decorrentes da cardiotoxicidade da DOX inclui a realização de ecocardiograma (ECO), exame este que deve ser realizado antes da quimioterapia, no decorrer do tratamento e anualmente após o término do mesmo (KREMER et al., 2013). A ecocardiografia é uma técnica não invasiva, que emprega o ultrassom para o exame do coração. O ECO pode ser utilizado para avaliar a estrutura e a função do coração, especialmente as funções sistólica e diastólica do ventrículo esquerdo. É um dos métodos diagnósticos mais utilizados para detectar cardiotoxidade por ANT nas fases precoces e tardias (ABOSOUDAH et al., 2011).

No monitoramento cardíaco com o ECO, principalmente na avaliação da FEVE (TSAl et al., 2011; MIYOSHI et al., 2014), em pacientes que não apresentam risco aumentado de cardiotoxicidade em tratamento com ANT, uma estimativa da FEVE depois de 4-5 ciclos de tratamento com DOX $\left(200-300 \mathrm{mg} / \mathrm{m}^{2}\right)$ pode identificar o paciente que desenvolve diminuição inesperada e assintomática da função sistólica. Isso deve ser considerado para o tratamento e reavaliação das opções terapêuticas. Critérios para o que constitui substancial diminuição da função sistólica em tais circunstâncias é objeto de debate. Alguns ensaios clínicos apontam que a diminuição de $15 \%$ no intervalo normal ou de $10 \%$ abaixo do limite inferior da FEVE deve ser considerada significativa, devendo desencadear resposta, quer sob a forma de nova avaliação clínica ou laboratorial, vigilância reforçada ou regime quimioterápico alternativo de menor potencial cardiotóxico (CARVER et al., 2007).

A ecodopplercardiografia é o exame mais indicado para o reconhecimento precoce da CMD e detecta inclusive as formas mais brandas, muitas vezes não detectadas em outros exames. Esse exame possibilita a obtenção de informações relacionadas ao tamanho e à função das câmaras, assim como à integridade valvar, à espessura das paredes a padrões de fluxo sanguíneo (FIGUEIRA, 2014). Por meio desse procedimento é possível acompanhar a dilatação cardíaca induzida pela DOX, 
avaliar a função sistólica ventricular e também comparar diferenças entre grupos tratados com antioxidantes (XIN et al., 2011).

O exame ecodopplercardiográfico consiste na avaliação cardíaca a partir de imagens ultrassonográficas apresentadas no modo bidimensional, modo $\mathrm{M}$ e modo Doppler. O modo bidimensional e o modo $\mathrm{M}$ fornecem informações sobre a morfologia das câmaras, como o diâmetro ventricular no final da diástole e na sístole, a partir dos quais se podem calcular vários índices funcionais miocárdicos. A utilização do Doppler permite avaliar a direção e a velocidade do fluxo sanguíneo nos vasos e no coração, que são parâmetros extremamente importantes no diagnóstico de anomalias congênitas (MADRON et al., 2015).

FERREIRA et al. (2007) avaliaram o efeito protetivo do licopeno na cardiotoxicidade induzida pela DOX. Para isso, utilizaram a ecocardiografia e a histopatologia como métodos diagnósticos. A DOX na dose acumulada de $16 \mathrm{mg} / \mathrm{kg}$ induziu cardiotoxicidade, que foi detectada pelo ECO e pela avaliação histopatológica. A suplementação com licopeno promoveu proteção aos cardiomiócitos, evidenciada pela redução das áreas de necrose. Porém, a disfunção cardíaca não foi prevenida, conforme avaliação ecocardiográfica.

GRANADOS-PRINCIPAL et al. (2010), XIN et al. (2011) e ZHENG et al. (2011) avaliaram a dilatação cardíaca induzida pela DOX por meio do exame ecodopplercardiográfico e relataram que o método é útil para avaliar a redução da cardiotoxicidade induzida pelo fármaco com o uso de substâncias antioxidantes, tendo em vista as observações na morfofisiologia cardíaca nos indivíduos tratados com diferentes substâncias de ação antioxidante.

OZTARHAN et al. (2011) compararam a ecocardiografia com os níveis de troponina na detecção precoce da cardiotoxicidade das ANT em crianças com leucemia e concluíram que, dentre estes, a ecocardiografia é o melhor método para a avaliação proposta. Ainda, ABOSOUDAH et al. (2011) avaliaram crianças sobreviventes de câncer e assintomáticas que foram expostas às ANT. Observaram que $16,8 \%$ apresentaram anormalidades ecocardiográficas em média 2,9 anos após o término da quimioterapia. Concluíram que a realização de exames ecocardiográficos periódicos pode revelar anormalidades que podem ser detectadas e tratadas precocemente, reduzindo os riscos de progressão para IC. Conclusão semelhante foi obtida por YEH et al., (2014), que avaliaram o custo benefício do monitoramento cardíaco de crianças tratadas com DOX, utilizando ecocardiografia a cada um, dois, cinco ou dez anos, com subsequente tratamento para doença cardíaca nos casos positivos de acordo com as orientações do American College of Cardiology Foundation/American Heart Association (YANCY et al., 2013).

\section{- Análises bioquímicas}

Marcadores cardíacos séricos têm sido investigados para monitorar a cardiomiopatia relacionada à ANT. Baixo custo, ampla disponibilidade e extensa validação em diversas doenças cardíacas (GAGGIN \& JANUZZI, 2013), os tornaram atraentes como ferramentas potencialmente sensíveis para a detecção de danos precoces por ANT. Apesar dos benefícios dos exames bioquímicos na identificação precoce de pacientes de alto risco que necessitam de tratamento ou alteração de estratégias do tratamento quimioterápico, esses biomarcadores não substituem os exames de imagem para avaliação da FEVE, e são necessárias validações adicionais antes da utilização generalizada e incorporação nos protocolos anticâncer (EWER \& EWER, 2010). 


\section{- A isoenzima creatinoquinase}

A creatinaquinase é uma enzima citoplasmática, composta por subunidades $\mathrm{M}$ e/ou $\mathrm{B}$, que associadas formam as isoenzimas creatinoquinase muscular (CK-MM), isoenzima creatinoquinase cardíaca (CK-MB) e a isoenzima creatinoquinase cerebral (CK-BB). Essa enzima age como regulador da produção de fosfatos de alta energia e como reguladora da utilização destes em tecidos contráteis, motivo pelo qual é encontrada em tecidos de alto consumo de energia, como as fibras musculares e os túbulos distais do rim (WANG et al., 2011).

A CK-MM é a principal isoenzima encontrada no músculo estriado esquelético e os níveis aumentam drasticamente após lesões musculares generalizadas, como na trombose ilíaca no gato ou na rabdomiólise (THRALL et al., 2015). A CK-MB é a isoforma encontrada no músculo cardíaco (KEHL et al., 2012). Os níveis dessa enzima são quantificados rotineiramente para o diagnóstico do infarto agudo do miocárdio em humanos, o que é incomum nos animais domésticos. Entretanto, outras causas de necrose miocárdica comumente diagnosticadas nos animais domésticos também liberam enzimas, como ocorre nas miocardites. Já as cardiomiopatias crônicas tendem a causar pouca alteração nas concentrações de CK-MB devido à meia-vida curta da enzima (THRALL et al., 2015).

Traços da CK-MB são encontrados também no músculo esquelético, de maneira que pacientes com lesão muscular podem apresentar elevação das concentrações absolutas de CK e discreta elevação da CK-MB (BURTIS \& BRUNS, 2012). A atividade sérica de CK total e CK-MB aumenta de quatro a oito horas após a lesão miocárdica, alcançanco o pico entre 12 e 24 horas, e retorna aos valores normais em 48 a 72 horas (KANAAN et al., 2014).

Alterações na atividade da CK têm sido relatadas após a administração de DOX em modelos experimentais. ASSUMPÇÃO (2011) investigou o perfil farmacocinético da DOX (6 mg/kg) administrada em solução aquosa e em microemulsão lipídica em ratos. A atividade da CK-MB foi avaliada nos dois grupos, antes e após a administração das formulações, com o objetivo de comparar a cardiotoxicidade dos produtos. Os valores de CK-MB do grupo que recebeu DOX na forma de microemulsão não apresentaram alterações significativas, com a conclusão de que a microemulsão modificou o acesso do fármaco nos locais susceptíveis aos seus efeitos tóxicos.

KRISHNMURTHY et al., (2015) avaliaram o efeito antioxidante do febuxostat, um inibidor de xantina-oxidase, em ratos tratados com dose acumulada de DOX de $15 \mathrm{mg} / \mathrm{kg}$. Os resultados mostraram que diante da DOX houve elevação dos níveis séricos de CK-MB e que o febuxostat reduziu significativamente os níveis séricos desse marcador de injúria cardíaca. Resultados semelhantes também foram observados no uso da vitamina E e do telmisartan (HADI et al., 2012). Outros estudos mostraram que os níveis séricos de CK-MB em modelos animais de cardiotoxicidade da DOX, aumentaram na ordem de $1200 \mathrm{U} / \mathrm{L}$ após 48 horas da aplicação de 20-25 mg/kg do fármaco (SINGH et al., 2008; ABDEL-RAHEEM \& ABDEL-GHANY, 2009). De acordo com os autores, esses resultados reafirmam o potencial cardiotóxico da DOX, bem como a utilidade da CK-MB como biomarcador diagnóstico para essa afecção.

\section{- Troponina cardíaca}

As células musculares cardíacas possuem sarcômeros, estes compostos de filamentos grossos e finos formados pelas proteínas miosina, actina, tropomiosina e troponina. As troponinas formam os filamentos finos do aparelho miofibrilar e são 
compostas de múltiplas subunidades: troponina I [subunidade inibidora da actina], troponina $\mathrm{C}$ [subunidade ligada ao cálcio e reguladora da contração] e troponina $T$ [subunidade ligada à miosina-tropomiosina] (JUNQUEIRA \& CARNEIRO, 2013). As isoformas mais utilizadas para o diagnóstico de necrose do miocárdio são as troponinas I e $\mathrm{T}$. A troponina $\mathrm{C}$ encontrada no músculo cardíaco é idêntica à do músculo estriado esquelético, o que dificulta sua utilização no diagnóstico diferencial (KANAAN et al., 2014). Mas diferente de outros biomarcadores de lesão cardíaca, as troponinas não estão presentes em grande parte dos soros normais. Porém, interferências nesses resultados foram apresentadas e justificadas pela captura de anticorpos marcados pela fibrina em amostras não totalmente coaguladas. Em função dessas interferências, tem sido preconizado o uso de plasma heparinizado nos testes que utilizam marcadores cardíacos (JAFFE, 2012).

Uma forma de avaliar as lesões cardíacas induzidas pela DOX é por meio da dosagem das troponinas I e $\mathrm{T}$, que são extremamente úteis no diagnóstico de lesões miocárdicas agudas. A troponina I cardíaca é um biomarcador de lesão miocárdica, uma vez que se localiza no complexo de contratilidade miocárdica, dentro do sarcômero. A elevação do nível plasmático da troponina I indica lesão miocárdica, mas não identifica o mecanismo envolvido na sua liberação. A lesão do miocárdio pode ocorrer por uma variedade de anormalidades, além das síndromes coronarianas agudas (CHRISTENSON \& CHRISTENSON, 2013). A troponina T, na maioria dos estudos, é apontada por apresentar melhor correlação com a dose acumulada do fármaco, mas estudos comparativos com testes altamente sensíveis ainda são necessários (REAGAN et al., 2013).

Em um estudo com 703 pacientes, a elevação de troponina I nos tempos zero, 72 horas e um mês após a administração da quimioterapia precedeu o declínio tardio da FEVE e uma variedade de eventos cardíacos (CARDINALE et al., 2004). Resultados similares também foram documentados com a troponina T (SAWAYA et al., 2012). LIPSHULTZ et al. (1997) observaram que o aumento da concentração sérica de troponina $\mathrm{T}$ logo após a aplicação de DOX foram associados ao risco subsequente de anormalidades do ventrículo esquerdo, como redução na espessura da parede e dilatação. Já HERMAN et al. (1999) utilizaram a determinação dos níveis séricos de troponina $\mathrm{T}$ para monitorar a extensão das lesões cardíacas induzidas pelas ANT. Os autores concluíram que os níveis séricos de troponina T aumentam conforme a gravidade das lesões e a dose acumulada. Dessa forma, a quantificação da troponina $\mathrm{T}$ tem sido utilizada como marcador precoce da cardiotoxicidade induzida pelas ANT e pode orientar modificações nos protocolos quimioterápicos relacionadas à dose ou intervalo entre as aplicações desses fármacos (KILICKAP et al., 2005).

Já no estudo de LONČAR-TURUKALO et al., (2015), a concentração de troponina I não aumentou no soro de ratos 35 dias após a interrupção do tratamento com DOX. Os autores justificam que possivelmente a lesão cardíaca ainda era incipiente ou a troponina I possui menor valor prognóstico em ratos. Em humanos, a dosagem de troponina cardíaca tem substituído a CK-MB como exame padrão para o diagnóstico precoce de lesão cardíaca após o início dos sintomas (WILLIAMSON \& SNYDER, 2013).

\section{- Peptídeo natriurético tipo $B$ (BNP)}

O BNP é detectado 24 a 48 horas após lesão miocárdica, com pico em 72 horas e eliminação após sete dias (WILLIAMSON \& SNYDER, 2013). O aumento na concentração sérica desse peptídeo ocorre em resposta à sobrecarga de volume ou 
pressão no coração. Os níveis de BNP também são elevados após a administração da ANT, e em geral correlacionam-se com índices ecocardiográficos de disfunção sistólica e diastólica, assim como insuficiência cardíaca clínica. No entanto, os níveis de BNP podem variar consideravelmente dependendo das características fisiológicas do paciente, o que torna difícil estabelecer valores de corte para a população em geral (EWER \& EWER, 2010). Um estudo aponta que o BNP é pouco sensível para detectar diminuições assintomáticas da FEVE em pacientes tratados com ANT em comparação a exames de imagem de alta sensibilidade (VOGELSANG et al., 2008). Entretanto, um estudo avaliou os níveis séricos de BNP em pacientes com carcinoma mamário em tratamento com ANT e constatou que a elevação de $\mathrm{BNP}$, o que implica em doença cardíaca subclínica pré-existente, foi associada à diminuição da FEVE em dois anos (FEOLA et al., 2011).

\section{- Histopatologia, microscopia eletrônica e imunoistoquímica}

Algumas das lesões microscópicas características da toxicidade miocárdica pela DOX são a fragmentação de miofibrilas, degeneração vacuolar miocítica (MOURA et al., 2015), fibrose, necrose e alteração no tamanho nuclear (PONTES et al., 2010). As lesões cardíacas ultramicroscópicas induzidas pela DOX se caracterizam por sobreposição das linhas $Z$ e encurtamento do sarcômero, miocitólise, edema, tumefação do sarcoplasma e organelas dissociadas em seu interior, tumefação e lise das cristas mitocondriais e redução das miofibrilas. No espaço extracelular notam-se fibroblastos e fibras colágenas (GAVA, 2014).

A progressão das lesões miocárdicas correlaciona-se às doses de ANT acumuladas. Nos estágios iniciais as alterações detectadas à histopatologia são focais e, com a progressão da cardiotoxicidade, há evolução para fibrose miocárdica difusa (OLIVEIRA, 2006). Diante de doses terapêuticas alterações histopatológicas podem não ser identificadas. DUDNAKOVÁ et al. (2003) aplicaram 2,2 mg/kg de DOX em ratos e fizeram eutanásia duas horas após a aplicação. Os autores observaram apenas edema perivascular no músculo cardíaco e o relacionaram ao tempo de análise pós-lesão.

PONTES et al. (2010) avaliaram lesões microscópicas no coração de ratos seis meses após a aplicação de $5 \mathrm{mg} / \mathrm{kg}$ de DOX e notaram fibrose miocárdica em $75 \%$ dos casos, vacuolização no citoplasma dos cardiomiócitos em $100 \%$, necrose miocárdica em $75 \%$ e variação no tamanho nuclear em $87 \%$ dos corações.

A dilatação cardíaca que ocorre após terapias prolongadas com DOX também implica em alterações da matriz extracelular (MEC). Os RL são responsáveis pela degradação dos cardiomiócitos e do colágeno. DUDNAKOVÁ et al. (2003) utilizaram a histopatologia, a microscopia eletrônica e a imunoistoquímica para avaliar o coração de ratos tratados com DOX. Observaram lesões típicas da ação do fármaco, incluindo fibrose difusa, apoptose, perda focal de elementos contráteis, alterações no citoesqueleto e drástica alteração na permeabilidade nuclear. Os autores ponderam que falência do sistema de microtúbulos e a alteração da arquitetura do citoesqueleto possivelmente relacionam-se à vacuolização sarcoplasmática observada nos cardiomiócitos dos ratos. Esses mesmos autores também identificaram por imunoistoquímica os colágenos tipo I, III e IV e avaliaram proteínas expressas nos cardiomiócitos, como a desmina, proteína associada à quinase (KRP), miosina de cadeia leve quinase (MLCK), tubulina, vinculina e fibronectina. Observaram que mesmo após aplicação única de DOX, em doses terapêuticas $(0,44$ a $2,2 \mathrm{mg} / \mathrm{kg})$, houve aumento na expressão de proteínas do 
citoesqueleto e da MEC, que podem não ser identificadas em exames morfológicos, sugerindo seu envolvimento na reparação cardíaca.

No estresse oxidativo e em outros processos patológicos pode haver desequilíbrio entre diversas proteases e antiproteases, resultando em alterações quantitativas e/ou qualitativas na composição da matriz e, consequentemente, em degradação da MEC, dilatação e remodelamento do miocárdio (SHAKER \& SOUROUR, 2010). De acordo com POTÁČOVÁ et al. (2007), o estresse oxidativo pode ativar as metaloproteinases de matriz (MMP), que são enzimas responsáveis pela degradação de componentes da MEC, atuando no desenvolvimento e remodelamento normais ou em processos patológicos (KHASIGOV et al., 2003). São mais de 25 enzimas classificadas em cinco famílias de diferentes especificidades ao substrato, denominadas colagenases (MMP1, MMP8, MMP13 e MMP18), gelatinases (MMP2 e MMP9), estromelisinas (MMP3, MMP10, MMP11 e MMP26), matrilisina (MMP7) e metaloproteinases de membrana (MMP14, MMP15, MMP16, MMP17, MMP24 e MMP25) (PAGE-MCCAW et al., 2007; VISSE \& NAGASE, 2003).

Anticorpos contra MMP2 e MMP9 e seus inibidores têm sido utilizados para avaliar o remodelamento do miocárdio na cardiotoxicidade induzida pela DOX, tanto na fase aguda (KIZAKI et al., 2006) quanto crônica (ADAMCOVÁ et al., 2010). Essas MMP desempenham importante função no desenvolvimento de diversas doenças cardiovasculares (KIZAKI et al., 2006). Alterações nos níveis de MMP2 e MMP9 no miocárdio foram observadas na CMD em humanos (THOMAS et al., 1998; SPINALE et al., 2000), em doenças hipertensivas utilizando ratos como modelo experimental (ROBERT et al., 1997), no infarto do miocárdio (PETERSON et al., 2000), bem como após tratamento agudo (KIZAKI et al., 2006) e crônico (ADAMCOVÁ et al., 2010) com DOX em coelhos.

Os inibidores de metaloproteinases (TIMP) são proteínas específicas que regulam a atividade das MMP, auxiliando na manutenção da integridade da MEC. São descritos quatro tipos de $\operatorname{TIMP}(1,2,3$ e 4), que diferem em estrutura, propriedades bioquímicas, expressão e funções biológicas (PARKS et al., 2004; PAGE-MCCAW et al., 2007). O equilíbrio entre a síntese e a ação das MMP e seus inibidores é fundamental para a manutenção da homeostase da MEC. Quando esse equilíbrio é rompido, a integridade da MEC é comprometida. A principal função fisiológica dos TIMP relaciona-se à regulação da degradação da MEC pelas MMP durante o desenvolvimento e a remodelação tecidual (HAYAKAWA \& YAMASHITA, 2003).

Os TIMP podem inibir todos os tipos de MMP ativas. Entretanto, há diferenças de afinidade entre os tipos de TIMP e MMP. Por exemplo, a TIMP1 inibe fortemente MMP7, MMP9, MMP1 e MMP3 (BOURBOULIA \& STETLERSTEVENSON, 2010). Por outro lado, a MMP2 é predominantemente inibida por TIMP2 (BEE et al., 2000) e TIMP4 (LIU et al., 1997).

Há um significativo interesse em inibir as MMP como estratégia terapêutica. Como o constante remodelamento é regulado pelas MMP, as quais recebem influência de fatores de crescimento e citocinas, estudos têm relacionado a atividade gelatinolítica das MMP a esses fatores. Nesse sentido, terapias anti-TNF têm sido relacionadas à redução do remodelamento cardíaco e dilatação cardíaca em humanos com IC. LI et al. (2000) testaram a ação do AdTNFRI, um anti-TNF, e notaram significativa redução na expressão das gelatinases MMP2 e 9. Já TIMP1 apresentou maior porcentagem de células marcadas. 


\section{Terapias antioxidantes}

Diretrizes baseadas em evidências para o tratamento da IC em geral têm sido publicadas (YANCY et al., 2013). Embora essas recomendações não tenham sido validadas para cardiomiopatia relacionada à quimioterapia de forma independente, um número crescente de evidências sugere uma via final comum na fisiopatologia da IC sistólica. Assim, pelo menos para as formas irreversíveis de cardiomiopatia relacionada à quimioterapia, a aplicação dessas orientações parece prudente. Se os tratamentos padrão para IC oferecem benefícios claros em casos de disfunção cardíaca reversível, ainda não se sabe (MANN, 2005).

Várias estratégias para a cardioproteção seletiva têm sido exploradas e demonstraram diferentes graus de sucesso. O grau de proteção depende da duração da infusão e o prolongamento desta é claramente cardioprotetor, mas esses esquemas de administração requerem bombas de infusão e cateteres. Infusões de 72-96 horas têm sido muito bem sucedidas no tratamento de um grande número de pacientes (EWER \& EWER, 2010).

Devido à utilidade das ANT no tratamento do câncer, bem como ao amplo potencial em produzir lesões induzidas por RL, esforços têm sido voltados na busca de terapias antioxidantes que possam reduzir o estresse oxidativo desses fármacos, sem alterar sua eficácia. Essa estratégia até o momento tem alcançado sucesso bastante modesto, indicando que $\mathrm{o}$ atual entendimento da cardiotoxicidade da DOX ainda é incompleto (RANEK \& WANG, 2010).

Vários compostos têm sido testados, especialmente os antioxidantes naturais (GRANADOS-PRINCIPAL et al., 2010). Fenois, flavonoides, tocoferois, fosfolipídios, aminoácidos, ácido fítico, ácido ascórbico, pigmentos e esterois são substâncias que possuem atividade antioxidante (ROESLER et al., 2007). Vários antioxidantes naturais podem ser extraídos de vegetais e plantas e são excelentes fontes de compostos fenólicos (ZHENG \& WANG, 2001), os quais apresentam inúmeras propriedades farmacológicas, incluindo antialergênicas, anti-inflamatórias, antimicrobianas, antitrombóticas, cardioprotetoras e vasodilatadoras (BALASUNDRAM et al., 2006).

O consumo de antioxidantes naturais, como os compostos fenólicos presentes na maioria das plantas, inibe a formação de $R L$ e tem sido associado à menor incidência de doenças relacionadas ao estresse oxidativo (BRITO, 2012; GUIMARÃES et al., 2015). LEE \& SHIBAMOTO (2002) evidenciaram que a atividade antioxidante dos compostos e ácidos fenólicos tem seus efeitos atribuídos à propriedade redox e estrutura química. Demonstraram ainda que os compostos fenólicos possuem um anel benzênico, um grupamento carboxílico e um ou mais grupamentos de hidroxila na molécula, conferindo-Ihes propriedades antioxidantes.

É possível encontrar na literatura estudos com substâncias antioxidantes naturais com o intuito de neutralizar os efeitos deletérios do estresse oxidativo e que, especificamente, relatam a redução da cardiotoxicidade pela DOX (OZDOĞAN et al., 2011; XIN et al., 2011). O ácido ascórbico (vitamina C), presente em frutas cítricas e algumas hortaliças, se destaca entre os antioxidantes naturais por ser considerado um dos mais potentes e menos tóxicos. É hidrossolúvel e encontrado em altas concentrações em diversos tecidos. É um eficaz neutralizador de $\mathrm{RL}$, já que reage com as ERO, oxidando-se a desidroascórbico e, pela ação da enzima dehidroascorbatoredutase, volta a se converter em ácido ascórbico (LIMA, 2008). A vitamina $C$ é utilizada para comparar o efeito protetivo de outros compostos contra os efeitos tóxicos da DOX (GRANADOS-PRINCIPAL et al., 2010). 
A vitamina $E$ agrupa compostos lipossolúveis como os tocoferois e tocotrienois, é constituinte das membranas celulares e possui elevada capacidade antioxidante (ALVAREZ-LEITE et al., 2011). Em altas doses, reduz a peroxidação lipídica e aberrações cromossômicas. De acordo com GRANADOS-PRINCIPAL et al. (2010), reduz a nefrotoxicidade induzida pela DOX e acelera a regeneração da pele. Já PURI et al. (2005) avaliaram o efeito da vitamina E na cardiotoxicidade induzida pela DOX em ratos. Avaliaram peso, ECG, níveis séricos de CK-MB, lactato desidrogenase (LDH) e transaminase glutâmico-oxalacética (TGO), também chamada de aspartato aminotransferase (AST). Concluíram que o pré-tratamento com vitamina $E$ reduz as alterações eletrocardiogáficas, os níveis de CK-MB e LDH aumentados devido à lesão miocárdica induzida pela DOX, mostrando evidências de que essa vitamina possui efeito protetor no miocárdio de ratos submetidos à cardiotoxicidade pela DOX.

XIN et al. (2011) investigaram o efeito protetivo do Lycium barbarum (açaí da china) na cardiotoxicidade induzida pela DOX em ratos. Os ratos do G1 receberam água e solução salina; os do G2 LPB (polissacarídeo de Lycium barbarum) e solução salina; os do G3 água e DOX; e os do G4 LPB e DOX. O LPB (200 mg/Kg) e a água destilada foram administrados por via oral durante 10 dias. A DOX $(10 \mathrm{mg} / \mathrm{Kg})$ e a solução salina $(0,9 \%, 10 \mathrm{ml} / \mathrm{kg})$ foram administradas por via intravenosa no dia sete após o início do experimento. Três dias após a aplicação da DOX realizaram-se exame eletrocardiográfico e análises bioquímicas, e os ratos foram submetidos à eutanásia para a avaliação morfológica. Os autores concluíram que o LPB propiciou significativo efeito protetivo na cardiotoxicidade induzida pela DOX possivelmente por supressão do estresse oxidativo.

OZDOĞAN et al. (2011) avaliaram o efeito antioxidante da carnosina, um dipeptídeo presente em tecidos mamíferos, particularmente nas fibras musculares esqueléticas, responsável pela neutralização de $R L$ e produtos da peroxidação lipídica das membranas celulares. Avaliaram pressão arterial, parâmetros hemodinâmicos, ECG, exames bioquímicos como CK, LDH, AST, alanina aminotransferase (ALT), quantificação das enzimas glutation peroxidase (GSH-Px), superóxido dismutase (SOD) e calalase (CAT), e mensuração da peroxidação lipídica pelo método de quantificação de substâncias reativas ao ácido tiobarbitúrico (TBARS). Segundo os autores, o tratamento com carnosina promove significativa redução da disfunção cardíaca induzida pela DOX, revelada pela normalização da função ventricular, ECG e exames bioquímicos.

KARIMI et al. (2005) avaliaram o efeito protetor do licopeno e do extrato de tomate na cardiotoxicidade induzida pela DOX, na dose de $15 \mathrm{mg} / \mathrm{kg}$, em aplicação única, via intraperitoneal em ratos. Os ratos foram submetidos à eutanásia após três dias da última aplicação de DOX. Os autores notaram que os animais tratados apenas com DOX apresentaram degeneração miocárdica de intensidade moderada a acentuada, esta acompanhada de infiltrado mononuclear. Ainda, esses danos ao miocárdio foram atenuados no coração dos ratos submetidos à aplicação de DOX, mas tratados com licopeno e extrato de tomate.

MOURA et al. (2015) testaram a ação do extrato etanólico da casca do pequi (EECP) na cardiotoxicidade induzida pela DOX em ratos. À análise histopatológica notaram que o EECP na dose de $600 \mathrm{mg} / \mathrm{kg}$ atenuou a degeneração vacuolar miocíttica, reduziu a quantidade de células de Anichkow e a fragmentação das miofibrilas, comprovando que este antioxidante natural pode neutralizar as lesões induzidas pela DOX. 
Além dos antioxidantes naturais, estão disponíveis no mercado fármacos antioxidantes que colaboram na prevenção e/ou redução da cardiotoxicidade pela DOX. O dexrazoxano, por exemplo, é um quelante de ferro quimicamente semelhante ao ácido etilenodiaminotetracético, com reconhecida ação protetora contra a cardiotoxicidade por ANT. Esse fármaco é o único aprovado por agências reguladoras para uso na prevenção de cardiomiopatia por ANT (ROCHETTE et al., 2015). Contudo, já foram levantadas dúvidas sobre o eventual comprometimento da eficácia do protocolo de terapia oncológica e o agente não obteve ampla aceitação no tratamento de rotina de pacientes tratados com ANT (EWER \& EWER, 2010).

A relação entre o ferro e a cardiotoxicidade pela ANT, além da produção de $\mathrm{RL}$, pode estar relacionada a alterações homeostáticas do ferro cardíaco que ocorrem através da interação da DOX com proteínas reguladoras do ferro (IRP). Isso modifica a expressão de proteínas essenciais para a manutenção dos níveis adequados de ferro intracelular (RINES \& ARDEHALI, 2013). Consequentemente, quelantes de ferro também podem interferir na interação da DOX com o ferro celular de forma mais complexa que apenas a reação de Fenton (ROCHETTE et al., 2015).

O probucol é outra droga que além de hipocolesterolemiante lipofílico, mimético da vitamina E, possui propriedades antioxidantes. WALKER et al. (2011) realizaram exame histopatológico para avaliar o efeito cardioprotetor do probucol contra a cardiotoxicidade por ANT e trastuzumab (TRZ). Dez dias após os tratamentos os ratos foram submetidos à eutanásia e as amostras cardíacas coradas com Tricrômico de Masson, com o objetivo de quantificar a fibrose miocárdica. Cinco dias após o início do experimento, degeneração e vacuolização das miofibrilas foram identificadas nos grupos que receberam DOX e DOX + TRZ. Os grupos que receberam o antioxidante probucol profilaticamente apresentaram mínima degeneração e vacuolização miofibrilar, o que contribuiu para comprovar a redução da cardiotoxicidade da DOX com o uso desse antioxidante.

A hesperidina, um antioxidante bioflavonoide cítrico, foi testado por ABDEL-RAHEEME \& ABDEL-GHANY (2009). No coração dos ratos que receberam $20 \mathrm{mg} / \mathrm{kg}$ de DOX, por via intraperitoneal, em dose única, os autores relataram edema, infiltrado inflamatório associado a hialinização dos cardiomiócitos, congestão dos vasos do pericárdio e hemorragia focal no miocárdio. De outra parte, observaram que o coração dos ratos que receberam pré-tratamento com hesperidina apresentaram alterações microscópicas de menor intensidade.

\section{CONSIDERAÇÕES FINAIS}

Apesar dos avanços no âmbito da medicina e medicina veterinária, especialmente no que diz respeito aos protocolos de terapia anticâncer, as ações citotóxicas de muitos fármacos utilizados nessas prescrições promovem lesões não somente nas células neoplásicas, mas também em células e tecidos normais. Exemplo disso são as ANT, agentes de poderosa ação antineoplásica, mas com reconhecido efeito tóxico ao organismo. As lesões desencadeadas por fármacos dessa natureza podem ser imediatas ou tardias, a exemplo das que ocorrem no miocárdio de pacientes tratados com DOX. Assim, o desafio atual tem sido reconhecer em detalhes os mecanismos de ação desses fármacos, estabelecer protocolos para o diagnóstico precoce das lesões produzidas pelos mesmos e ainda encontrar caminhos que permitam prevenir ou atenuar os efeitos tóxicos sobre células normais, sem interferir no potencial quimioterápico do agente antitumoral.

Não se trata de tarefa fácil, entretanto, a disponibilidade de métodos como a radiografia, eletrocardiografia, ecocardiografia, biopsia miocárdica e os exames 
bioquímicos têm auxiliado na busca do melhor a oferecer a pacientes que necessitam do tratamento anticâncer para a cura ou aumento da sobrevida diante de uma enfermidade neoplásica. Somado a isso, destacam-se as pesquisas envolvendo o uso de antioxidantes como agentes auxiliares na prevenção e redução dos efeitos tóxicos desses fármacos antitumorais, particularmente no que se refere aos efeitos cardiotóxicos induzidos pela DOX.

\section{REFERÊNCIAS}

ABDEL-RAHEEM, I. T.; ABDEL-GHANY, A. A. Hesperidin alleviates doxorubicininduced cardiotoxicity in rats. Journal of the Egyptian National Cancer Institute, v. 21, n. 2, p. 175-184, 2009.

ABOSOUDAH, I.; GREENBERG, M. L.; NESS, K. K.; BENSON L.; NATHAN P. C. Echocardiographic surveillance for asymptomatic late-onset anthracycline cardiomyopathy in childhood cancer survivors. Pediatric Blood and Cancer, v. 57, n. 3, p. 467-472, 2011.

ADAMCOVÁ, M.; POTÁCOVÁ, A.; POPELOVÁ, O.; STERBA, M.; MAZUROVÁ, Y.; AUPPERLE, H.; GERSI, V. Cardiac remodeling and MMPs on the model of chronic daunorubicin-induced cardiomyopathy in rabbits. Physiological Research, v. 59, n. 5, p. 831-836, 2010.

AEBI, S.; DABIDSON, T.; GRUBER, G.; CARDOSO, G. Primary breast cancer: ESMO Clinical Practice Guidelines for diagnosis, treatment and follow-up. Annals of Oncology, v. 22, n. Supplement 6, p. vi12-vi24, 1 set. 2011.

ALVAREZ-LEITE, J. I.; PEREIRA, S. S.; VIEIRA, E. C. Doenças Nutricionais. In: BRASILEIRO FILHO, G. (Ed.). Bogliolo - Patologia. $8^{a}$. ed. Rio de Janeiro, RJ: Guanabara-Koogan, 2011. p. 1524.

ARMENIAN, S. H.; HUDSON, M. M.; MULDER, R. L.; CHEN, M. H.; CONSTIINE, L. S.; DWYER, M.; NATHAN, P. C.; TISSING, W. J. E. Recommendations for cardiomyopathy surveillance for survivors of childhood cancer: a report from the International Late Effects of Childhood Cancer Guideline Harmonization Group. The Lancet Oncology, v. 16, n. 3, p. e123-e136, mar. 2015.

ASSUMPÇÃO, J. U. C. V. Farmacocinética pré-clínica e cardiotoxicidade da doxorrubicina veiculada por sistema microemulsionado. [s.l.] Dissertação (Mestrado em Ciências Farmacêuticas). Araraquara: Universidade Estadual Paulista; 2011.

BALASUNDRAM, N.; SUNDRAM, K.; SAMMAN, S. Phenolic compounds in plants and agri-industrial by-products: Antioxidant activity, occurrence, and potential uses. Food Chemistry, v. 99, n. 1, p. 191-203, 2006.

BARRETT-LEE, P. J.; DIXON, J. M.; FARRELL, C.; JONES, A.; LEONARD, R.; MURRAY, N.; PAMIERI, C.; PLUMMER, C. J.; STANLEY, A.; VERRILL, M. W. Expert opinion on the use of anthracyclines in patients with advanced breast cancer 
at cardiac risk. Annals of oncology $\square$ : official journal of the European Society for Medical Oncology / ESMO, v. 20, n. 5, p. 816-827, 2009.

BASILE, A. L. C. Avaliações ecodopplercardiográfica, eletrocardiográfica computadorizada, radiográfica e morfométrica em cães adultos da raça Bulldog Inglês. [s.l.] Dissertação (Mestrado em Ciência Animal) - Universidade Federal de Goiás, Goiânia, 2008.

BEE, A.; BARNES, A.; JONES, M. D.; ROBERSON, D. H.; CLEGG, P. D.; CARTER, S. D. Canine TIMP-2: purification, characterization and molecular detection. Vet J, v. 160 , n. 2, p. 126-134, 2000.

BILLINGHAM, M. E.; MASON, J. W.; BRISTOW, M. R.; DANIELS, J. R. Anthracycline cardiomyopathy monitored by morphologic changes. Cancer treatment reports, v. 62, n. 6, p. 865-872, 1978.

BOURBOULIA, D.; STETLER-STEVENSON, W. G. Matrix metalloproteinases (MMPs) and tissue inhibitors of metalloproteinases (TIMPs): Positive and negative regulators in tumor cell adhesion. Seminars in Cancer Biology, 2010.

BRITO, N. J. N. Benefícios dos antioxidantes naturais no estresse oxidativo. Revista Facider, v. 1, n. 1, p. 1-16, 2012.

BURTIS, C. A.; BRUNS, D. E. Tietz textbook of clinical chemistry and molecular diagnostics. $5^{\text {a }}$. ed. Canadá. Elsevier Saunders Publisher, 2012. p. 2448

CARDINALE, D.; SANDRI, M T.; MARTINONI, A.; BORGHINI, E.; CIVELLI, M.; LAMANTIA, G.; CINIERI, S.; MARTINELLI, G.; FIORENTINI, C.; CIPOLLA, C. M. Myocardial injury revealed by plasma troponin I in breast cancer treated with highdose chemotherapy. Annals of Oncology, v. 13, n. 5, p. 710-715, 2002.

CARDINALE, D.; SANDRI, M. T.; COLOMBO, A.; COLOMBO, N.; BOERI, M.; LAMANTIA, G. Prognostic value of troponin I in cardiac risk stratification of cancer patients undergoing high-dose chemotherapy. Circulation, v. 109, n. 22, p. 27492754, 2004.

CARDOSO, M. J. L.; CALUDINO, J. L.; MELUSSI, M. Mensuração do tamanho cardíaco pelo método VHS (vertebral heart size) em cães sadios da raça American pit bull terrier. Ciência Rural, Santa Maria, v. 41, n. 1, p. 127-131, 2011.

CARVALHO, F. S.; BURGEIRO, A.; GARCIA, R.; MORENO, A. J.; CARVALHO, R. A.; OLIVEIRA, P. J. Doxorubicin-Induced Cardiotoxicity: From Bioenergetic Failure and Cell Death to Cardiomyopathy. Medicinal Research Reviews, v. 34, n. 1, p. 106-135, 2014.

CARVER, J. R.; SHAPIRO, C. L.; NG, A.; JACOBS, L.; SCHUWARTZ, C.; VIRGO, K. S.; HAGERTY, K. L.; SOMERFIELD, M. R.; VAUGHN, D. J. American Society of Clinical Oncology Clinical Evidence Review on the Ongoing Care of Adult Cancer Survivors: Cardiac and Pulmonary Late Effects. Journal of Clinical Oncology, v. 25, n. 25, p. 3991-4008, 1 set. 2007. 
CHRISTENSON, E.; CHRISTENSON, R. H. Characteristics of cardiac troponin measurements. Coronary Artery Disease, v. 24, n. 8, p. 698-704, dez. 2013.

CREUTZIG, U.; VAN DEN HEUVEL-EIBRINK, M. M.; GIBSON, B.; DWORZAK, M. N.; ADACHI, S.; DE BONT, E.; HARBOTT, J.; HASLE, H.; JOHNSTON, D.; KINOSHITA, A.; LEHRNBECHER, T.; LEVERGER, G.; MEJSTRIKOVA, E.; MESHINCHI, A.; PESSION, A.; RAIMONDI, S. C.; SUNG, L.; STARY, J.; ZWAAN, C. M.; KARPERS, G. J. L. Diagnosis and management of acute myeloid leukemia in children and adolescents: Recommendations from an international expert panel. Blood, v. 120, n. 16, p. 3187-3205, 2012.

CURIGLIANO, G.; CARDINALE, D.; SUTER, T.; PLATANIOTIS, G.; DE AZAMBUJA, E.; SANDRI, M. T.; CRISCITIELLO, C.; GOLDHIRSCH, A.; CIPOLLA, C. Cardiovascular toxicity induced by chemotherapy, targeted agents and radiotherapy: ESMO clinical practice guidelines. Annals of Oncology, v. 23, n. SUPPL. 7, 2012.

DUDNAKOVÁ, T. V.; LAKOMKIN, V. L.; TSYPLENKOVA, V. G.; SHEKHONIN, B. V.; SHIRINSKY, V. P.; KAPELKO, V. I. Alterations in myocardial cytoskeletal and regulatory protein expression following a single Doxorubicin injection. Journal of cardiovascular pharmacology, v. 41, n. 5, p. 788-794, 2003.

EARLE, C. C. Cancer Survivorship Research and Guidelines: Maybe the Cart Should Be Beside the Horse. Journal of Clinical Oncology, v. 25, n. 25, p. 3800-3801, 1 set. 2007.

ESCHENHAGEN, T.; FORCE, T.; EWER, M. S.; DE KEULENAER G. W.; SUTER, T. M.; ANKER, S. D.; AVKIRAN, M.; AZAMBUJA, E.; BALLIGAND, J.; BRUTSAERT, D. L.; CONDORELLI, G.; HANSEN, A. et al. Cardiovascular side effects of cancer therapies: A position statement from the Heart Failure Association of the European Society of Cardiology. European Journal of Heart Failure, v. 13, n. 1, p. 1-10, 2011.

EWER, M. S.; BENJAMIN, R. Formulae for Predicting the Likelihood of Developing Congestive Heart Failure Following Anthracycline Chemotherapy: Added Evidence for Early Cardiotoxicity. Journal of Cardiac Failure, v. 11, n. 6, p. S159, ago. 2005.

EWER, M. S.; EWER, S. M. Cardiotoxicity of anticancer treatments: what the cardiologist needs to know. Nature Reviews Cardiology, v. 7, n. 10, p. 564-575, out. 2010.

EWER, M. S.; PEREZ, E. A.;BASELGA, J.; BELL, R.; BRUTSAERRT, D.; MARTY, M.; PIENKOWSKI, T.; SUTER, T. M. P176 Cardiac safety guidelines for the adjuvant use of trastuzumab (Herceptin $\AA$ ) in HER2-positive early breast cancer. The Breast, v. 16, p. S63, mar. 2007.

FEOLA, M.; GARRONE, O.; OCCELLI, M.; FRANCINI, A.; BIGGI, A.; VISONTI, G.; ALBRILE, F.; BOBBIO, M.; MERLANO, M. Cardiotoxicity after anthracycline chemotherapy in breast carcinoma: Effects on left ventricular ejection fraction, troponin i and brain natriuretic peptide. International Journal of Cardiology, v. 148, n. 2, p. 194-198, 2011. 
FERREIRA, A. L. A.; RUSSELL, R. M.; ROCHA, N.; LADEIRA, M. S. P.; SALVADORI, D. M. F.; NASCIMENTO, M. C. M. O.; MATSUI, M.; CARVALHO, F. A.; TANG, G.; MATSUBARA, L.S.; MATSUBARA, B. B. Effect of lycopene on doxorubicin-induced cardiotoxicity: An echocardiographic, histological and morphometrical assessment. Basic and Clinical Pharmacology and Toxicology, v. 101, n. 1, p. 16-24, 2007.

FIGUEIRA, C. C. Ultrassonografia em pequenos animais. $1^{\mathrm{a}}$. ed. São Paulo, SP: Roca, 2014.

FILIPPI, L. H. O eletrocardiograma na medicina veterinária. São Paulo, SP: Roca, 2011.

FORREST, R. A.; SWIFT, L. P.; REPHAELI, A.; NUDELMAN, A.; KIMURA, K.; PHILIPS, D. R.; CUTTS, S. M. Activation of DNA damage response pathways as a consequence of anthracycline-DNA adduct formation. Biochemical Pharmacology, v. 83, n. 12, p. 1602-1612, 2012.

GAGGIN, H. K.; JANUZZI, J. L. Biomarkers and diagnostics in heart failure. Biochimica et Biophysica Acta - Molecular Basis of Disease, v. 1832, n. 12, p. 2442-2450, 2013.

GAMMELLA, E.; MACCARINELLI, F.; BURATTI, P.; RECALCATI, S.; CAIRO, G. The role of iron in anthracycline cardiotoxicity. Frontiers in Pharmacology, v. 5 FEB, $n$. February, p. 1-6, 2014.

GAVA, F. N. Remodelamento do miocárdio na cardiomiopatia dilatada induzida com doxorrubicina em coelhos. [s.I.] Tese (Doutorado em Medicina Veterinária). Jaboticabal: Universidade Estadual Paulista; 2014.

GÖRLACH, A.; KLAPPA, P.; KIETZMANN, T. The endoplasmic reticulum: folding, calcium homeostasis, signaling, and redox control. Antioxidants \& redox signaling, v. 8, n. 9-10, p. 1391-1418, 2006.

GRAHAM, J. P.; KEALY, K. J.; MCALLISTER, H. Radiologia e ultra-sonografia do cão e do gato. $5^{\mathrm{a}}$. ed. Barueri, SP: Manole, 2012.

GRANADOS-PRINCIPAL, S.; QUILES, J. L.; RAMIREZ-TORTOSA, C. L.; SANCHEZ-ROVIRA, P.; RAMIREZ-TORTOSA, M. C. New advances in molecular mechanisms and the prevention of adriamycin toxicity by antioxidant nutrients. Food and Chemical Toxicology, 2010.

GROARKE, J. D.; NOHRIA, A. Anthracycline Cardiotoxicity: A New Paradigm for an Old Classic. Circulation, p. 1946-1950, 2015.

GUIMARÃES, M. C.; ALVES, M. L. C; DE PAULA, L. C.; VIEIRA, E. C. S.; GARCIA, L. G. C.; DA SILVA, M. M. M.; DA SILVA, E. P.; DAMIANI, C. Avaliação da atividade antioxidante in vitro de cagaita madura. Revista de Biotecnologia \& Ciência, v. 4, n. 1, 2015. 
GUO, R. M.; XU, W. M.; LIN, J. C.; MO, L. Q.; HUA, X. X.; CHEN, P. X.; WU, K.; ZHENG, D. D.; FENG, J. Q. Activation of the p38 MAPK/NF-kB pathway contributes to doxorubicin-induced inflammation and cytotoxicity in $\mathrm{H} 9 \mathrm{c} 2$ cardiac cells. Molecular medicine reports, v. 8, n. 2, p. 603-8, 2013.

HADI, N.;YOUSIF, N.; AL-AMRAN, F. G.; HUNTEI, N. K.; MOHAMMAD, B. I.; ALI, S. $J$. Vitamin $E$ and telmisartan attenuates doxorubicin induced cardiac injury in rat through down regulation of inflammatory response. BMC Cardiovascular Disorders, 2012.

HAYAKAWA, T.; YAMASHITA, K. Structures and functions of tissue inhibitors of metalloprotinases. In: OAKAZAKI, I. et al. (Eds.). . Extracellular Matrix and the Liver: Approach to Gene Therapy. $1^{\mathrm{a}}$. ed. Nova York, NY: Elsevier, 2003. p. 309329.

HERMAN, E. H.; ZHANG, J.; LIPSHULTZ, S. E.; RIFAI, N.; CHADWICK, D.; TADEDA, K.; YU, Z. X.; FERRANS, V. J. Correlation between serum levels of cardiac troponin- $T$ and the severity of the chronic cardiomyopathy induced by doxorubicin. Journal of Clinical Oncology, v. 17, n. 7, p. 2237-2243, 1999.

JAFFE, A. S. Troponin-Past, Present, and Future. Current Problems in Cardiology, v. 37, n. 6, p. 209-228, jun. 2012.

JAIN, D. Cardiotoxicity of doxorubicin and other anthracycline derivatives. Journal of Nuclear Cardiology, v. 7, n. 1, p. 53-62, fev. 2000.

JONES, A. L.; BARLOW, M.; BARRETT-LEE, P. J.; CANNY, P. A.; GILMOUR, I. M.; ROBB, S. S.; PLUMMER, C. J.; WARDLEY, A. M.; VERRILL, M. W. Management of cardiac health in trastuzumab-treated patients with breast cancer: updated United Kingdom National Cancer Research Institute recommendations for monitoring. British journal of cancer, v. 100, n. 5, p. 684-692, 2009.

JUNQUEIRA, L. C.; CARNEIRO, J. Histologia básica: texto/atlas. 12ª . ed. Rio de Janeiro, RJ: Guanabara-Koogan, 2013.

KANAAN, S.; TERRA, M. A.; SARAMAGO, R. H.; XAVIER, A. R.; SILVA, M. L.; BENJO, A. M. Bioquímica clínica. 2ª . ed. São Paulo, SP: Atheneu, 2014.

KARIMI, G.; RAMEZANI, M.; ABDI, A. Protective effects of lycopene and tomato extract against doxorubicin-induced cardiotoxicity. Phytotherapy Research, v. 19, n. 10, p. 912-914, 2005.

KEHL, D. W.; IQBAL, N.; FARD, A.; KIPPER, B. A.; LANDA, A. P.; MAISEL, A. S. Biomarkers in acute myocardial injury. Translational research $\square$ : the journal of laboratory and clinical medicine, v. 159, n. 4, p. 252-64, 2012.

KHASIGOV, P. Z.; PODOBED, O. V.; GRACHEVA, T. S.; SALBIEV, K. D.; GRACHEV S. V.;; BEREZOV, T. T. Role of matrix metalloproteinases and their inhibitors in tumor invasion and metastasis. Biochemistry. Biokhimiia, v. 68, n. 7, p. 711-717, 2003. 
KILICKAP, S.; BARISTA, I.; AKGUL, E.; AYTEMIR, K.; AKSOYEK, S.; AKSOY, S.; CELIK, I.; KES, S.; TEKUZMAN, G. cTnT can be a useful marker for early detection of anthracycline cardiotoxicity. Annals of Oncology, v. 16, n. 5, p. 798-804, 2005.

KITTIWARAWUT, A.; VORASETTAKARNKIJ, Y.; TANASANVIMON, S.; MANASNAYAKORN, S.; SRIURANPONG V. Serum NT-proBNP in the early detection of doxorubicin-induced cardiac dysfunction. Asia-Pacific Journal of Clinical Oncology, v. 9, n. 2, p. 155-161, 2013.

KIZAKI, K.; ITO, R.; OKADA, M..; YOSHIOKA, K.; UCHIDE, T.; TEMMA, K.; MUTOH, K. I.; UECHI, M.; HARA, Y. Enhanced gene expression of myocardial matrix metalloproteinases 2 and 9 after acute treatment with doxorubicin in mice. Pharmacological Research, v. 53, n. 4, p. 341-346, 2006.

KREMER, L. C. M.; MULDER, R. L.; OEFFINGER, K. C.; BHATIA, S.; LANDIER, W.; LEVITT, G.; CONSTINE, S. L.; WALLACE, W. H.; CARON, H. N.; ARMENIAN, S. H.; SKINNER, R.; HUDSON, M. M.. A worldwide collaboration to harmonize guidelines for the long-term follow-up of childhood and young adult cancer survivors: A report from the international late effects of Childhood Cancer Guideline Harmonization Group. Pediatric Blood and Cancer, v. 60, n. 4, p. 543-549, 2013.

KRISHNAMURTHY, B.; RANI, N.; BHARTI, S.; GOLECHHA, M.; BHATIA, J.; NAG, T. C.; RAY, R.; ARAVA, S.; ARYA, D. S.. Febuxostat ameliorates doxorubicininduced cardiotoxicity in rats. Chemico-Biological Interactions, v. 237, p. 96-103, 2015.

LARSEN, R. L.; JAKACKI, R. I.; VETTER, V. L.; MEADOWS, A. T.; SILBER, J. H.; BARBER, G. Electrocardiographic changes and arrhythmias after cancer therapy in children and young adults. The American journal of cardiology, v. 70, n. 1, p. 7377, 1992.

LEE, K. G.; SHIBAMOTO, T. Determination of antioxidant potential of volatile extracts isolated from various herbs and spices. Journal of Agricultural and Food Chemistry, v. 50, n. 17, p. 4947-4952, 2002.

LI, Y. Y.; MCTIERNAN, C. F.; FELDMAN, A. M. Interplay of matrix metalloproteinases, tissue inhibitors of metalloproteinases and their regulators in cardiac matrix remodeling. Cardiovascular Research, v, 46, n. 2, p. 214-224, 2000.

LIMA, A. Caracterização química, avaliação da atividade antioxidante in vitro e in vivo, e identificação dos compostos fenólicos presentes no pequi. [s.l.] Tese (Doutorado em Ciências Farmacêuticas). São Paulo: Universidade de São Paulo; 2008.

LIPSHULTZ, S. E.; RIFAI, N.; SALLAN, S. E.; LIPSITZ, S. R.; DALTON, V.; SACKS, D. B.; OTTLINGER, M. E. Predictive value of cardiac troponin $T$ in pediatric patients at risk for myocardial injury. Circulation, v. 96, n. 8, p. 2641-2648, 1997.

LIU, Y. E.; WANG, M.; GREENE, J.; SU, J.; ULLRICH, S.; LI, H.; SHENG, S.; ALEXANDER, P.; SANG, Q. A.; SHI, Y. E. Preparation and characterization of 
recombinant tissue inhibitor of metalloproteinase 4 (TIMP-4). The Journal of biological chemistry, v. 272, n. 33, p. 20479-20483, 1997.

LONČAR-TURUKALO, T.; VASIĆ, M.; TASIĆ, T.; MIJATOVIĆ, G.; GLUMAC, S.; BAJIĆ, D.; JAPUNŽIĆ-ŽIGON, N. Heart rate dynamics in doxorubicin-induced cardiomyopathy. Physiological Measurement, v. 36, n. 4, p. 727-739, 2015.

LUBIENIECKA, J. M.; GRAHAM, J.; HEFFNER, D.; MOTTUS, R.; REID, R.; HOGGE, D.; GRIGLIATTI, T. A.; RIGGS, W. K. A discovery study of daunorubicin induced cardiotoxicity in a sample of acute myeloid leukemia patients prioritizes P450 oxidoreductase polymorphisms as a potential risk factor. Frontiers in Genetics, v. 4, 2013.

MADRON, E.; CHETBOUL, V.; BUSSADORI, C. Clinical Echocardiography of the Dog and Cat. $1^{\text {a }}$. ed. Oxford, Reino Unido: Elsevier Health Science, 2015.

MANN, D. L. Mechanisms and Models in Heart Failure: The Biomechanical Model and Beyond. Circulation, v. 111, n. 21, p. 2837-2849, 31 maio 2005.

MENNA, P.; PAZ, O. G.; CHELLO, M.; COVINO, E.; SALVATORELLI, E.; MINOTTI, G. Anthracycline cardiotoxicity. Expert Opinion on Drug Safety, v. 11, n. S1, p. S21-S36, maio 2012.

MIDDLEMAN, E.; LUCE, J.; FREI, E. Clinical trials with adriamycin. Cancer, v. 28, n. 4, p. 844-850, 1971.

MIYOSHI, T.; TANAKA, H.; KANEKO, A.; TATSUMI, K.; MATSUMOTO, K.; MINAMI, H.; KAWAI, H.; HIRATA, K. I. Left ventricular endocardial dysfunction in patients with preserved ejection fraction after receiving anthracycline. Echocardiography, v. 31, n. 7, p. 848-857, 2014.

MONTEIRO, J. P.; OLIVEIRA, P. J.; JURADO, A. S. Mitochondrial membrane lipid remodeling in pathophysiology: A new target for diet and therapeutic interventions. Progress in Lipid Research, v. 52, n. 4, p. 513-528, 2013.

MOURA, L. R.; FALEIRO, M. B. R.; CONCEIÇÃO, E. C.; ORPINELLI, S. R. T.; SANTIN, A. P. I.; MOURA, V. M. B. D. Ação do extrato da casca do pequi (Caryocar brasiliense) na cardiotoxicidade crônica induzida por doxorrubicina em ratos. Anais do $3^{\circ}$ Congresso Brasileiro de Patologia Veterinaria. Anais...Belo Horizonte, MG: 2015

NOEMAN, S. A.; HAMOODA, H. E.; BAALASH, A. A. Biochemical Study of Oxidative Stress Markers in the Liver, Kidney and Heart of High Fat Diet Induced Obesity in Rats. Diabetology \& Metabolic Syndrome, v. 3, p. 17, 2011.

OLIVEIRA, H. M. Avaliação da cardiotoxicidade tardia induzida por antraciclinas em crianças após tratamento de leucemia linfocítica aguda. [s.l.] Dissertação (Mestrado em Medicina - Pediatria) - Universidade Federal de Minas Gerais, Belo Horizonte, 2006. 
OZDOĞAN, K.; TAŞKIN, E.; DURSUN, N. Protective effect of carnosine on adriamycin-induced oxidative heart damage in rats. Anadolu kardiyoloji dergisi (The Anatolian journal of cardiology), v. 11, n. 1, p. 3-10, 2011.

OZTARHAN, K.; GULER, S.; AKTAS, B.; ARSLAN, M.; SALCIOGLU, Z.; AYDOGAN, $G$. The value of echocardiography versus cardiac troponin I levels in the early detection of anthracycline cardiotoxicity in childhood acute leukemia: prospective evaluation of a 7-year-long clinical follow-up. Pediatric hematology and oncology, v. 28, n. 5, p. 380-394, 2011.

PAGE-MCCAW, A.; EWALD, A. J.; WERB, Z. Matrix metalloproteinases and the regulation of tissue remodelling. Nature Reviews Molecular cell biology, v. 8, n. 3, p. 221-233, 2007.

PARKS, W. C.; WILSON, C. L.; LÓPEZ-BOADO, Y. S. Matrix metalloproteinases as modulators of inflammation and innate immunity. Nature Reviews Immunology, $v$. 4, n. 8, p. 617-629, ago. 2004.

PETERSON, J. T.; DILLON L. H. L.; BRYANT, J. W. Evolution of matrix metalloprotease and tissue inhibitor expression during heart failure progression in the infarcted rat. Cardiovascular Research, v. 46, n. 2, p. 307-315, 2000.

POLEGATO, B. F.; MINICUCCI, M. F.; AZEVEDO, P. S.; CARVALHO, R. F.; CHIUSO-MINICUSSI, F.; PEREIRA, E. J.; PAIVA, S. A. R.; ZOMOFF, L. A. M.; OKOSHI, M. P.; MATSUBARA, B. B.; MATSUBARA, L. S. Acute DoxorubicinInduced Cardiotoxicity is Associated with Matrix Metalloproteinase-2 Alterations in Rats. Cellular Physiology and Biochemistry, v. 35, n. 5, p. 1924-1933, 2015.

PONTES, J. C. D. V.; JÚNIOR, J. F. G.; SILVA, G. V. R.; BENFATTI, R. A.; DIAS, A. E. M. A. S.; DUARTE, J. J.; GARDENAL, N.; ODASHIRO, M.; SANTOS, C. H. M. Anatomopathological study of cardiomyopathy induced by doxorubicin in rats. Acta Cirurgica Brasileira, v. 25, n. 2, p. 137-143, abr. 2010.

POTÁČOVÁ, A.; ADAMCOVÁ, M.; STERBA, M.; POPELOVÁ, O.; SIMU゚NEK, T.; MAZUROVÁ, Y.; GUNCOVÁ, I.; GERSL, V. A pilot study of matrix metalloproteinases on the model of daunorubicin-induced cardiomyopathy in rabbits. Acta medica (Hradec Kralove) / Universitas Carolina, Facultas Medica Hradec Kralove, v. 50, n. 2, p. 109-111, 2007.

PURI, A.; MAULIK, S. K.; RAY, R.; BHATNAGAR, V. Electrocardiographic and biochemical evidence for the cardioprotective effect of vitamin $E$ in doxorubicininduced acute cardiotoxicity in rats. European Journal of Pediatric Surgery, v. 15, n. 6, p. 387-391, 2005.

RANEK, M. J.; WANG, X. Activation of the Ubiquitin Proteasome System in Doxorubicin Cardiomyopathy. Curr Hypertens Rep., v. 11, n. 6, p. 389-395, 2010.

REAGAN, W. J.; YORK, M.; BERRIDGE, B.; SCHULTZE, E.; WALKER, D.; PETTIT, $\mathrm{S}$. Comparison of Cardiac Troponin I and $\mathrm{T}$, Including the Evaluation of an 
Ultrasensitive Assay, as Indicators of Doxorubicin-induced Cardiotoxicity. Toxicologic Pathology, v. 41, n. 8, p. 1146-1158, 1 dez. 2013.

RINES, A. K.; ARDEHALI, H. Transition metals and mitochondrial metabolism in the heart. Journal of Molecular and Cellular Cardiology, v. 55, n.1, p. 50-57, 2013.

ROBERT, V.; BESSE, S.; SABRI, A.; SILVESTRE, J. S.; ASSAYAG, P.; NGUYEN, V. T.; SWYNGHDAUW, B.; DELCAYRE, C. Differential regulation of matrix metalloproteinases associated with aging and hypertension in the rat heart. Lab Invest, v. 76, n. 5, p. 729-738, 1997.

ROCHETTE, L.; GUENANCIA, C.; GUDJONCIK, A.; HACHET, O.; ZELLER, M.; COTTIN, Y.; VERGELY C. Anthracyclines/trastuzumab: new aspects of cardiotoxicity and molecular mechanisms. Trends in Pharmacological Sciences, v. 36, n. 6, 2015.

ROESLER, R.; MALTA, L, G.; CARRASCO, L. C.; HOLANDA, R. B.; SOUSA, C. A. S.; PASTORE, G. M.. Atividade antioxidante de frutas do cerrado. Ciência e Tecnologia de Alimentos, v. 27, n. 1, p. 53-60, mar. 2007.

SALAZAR-MENDIGUCHÍA, J.; GONZÁLEZ-COSTELLO, J.; ROCA, U.; ARIZASOLÉ, A.; MANITO, N.; CEQUIE, A. Anthracycline-mediated cardiomyopathy: Basic molecular knowledge for the cardiologist. Archivos de cardiologia de Mexico, v. 84, n. xx, p. 6-11, 2014.

SANTOS, A. DOS; MESQUITA, E. Cardioncologia: anormalidades eletrocardiográficas em pacientes com cardiomiopatia pós-uso de doxorrubicina. Rev. Scocerj, v. 22, n. 5, p. 281-288, 2009.

SAWAYA, H.; SEBAG, I. A.; PLANA, J. C.; JANUZZI, J. L.; KY, B.; TAN, T. C.; COHEN, V.; BANCHS, J.; CARVER, J. R.; WIEGERS, S. E.; MARTIN, R. T.; PICARD, M. H.; GERSZTEN, T. E.; HALPERN, E. F.; PASSERI, J.; KUTER, I.; SCHERRER-CROSBIE, M. Assessment of echocardiography and biomarkers for the extended prediction of cardiotoxicity in patients treated with anthracyclines, taxanes, and trastuzumab. Circulation: Cardiovascular Imaging, v. 5, n. 5, p. 596-603, 2012.

SCHOEN, F. J.; MITCHELL, R. N. O Coração. In: ABBAS, A. K. et al. (Eds.). . Patologia: Bases Patológicas das Doenças. $8^{a}$. ed. Rio de Janeiro, RJ: Elsevier, 2010. p. 587.

SHAKER, O.; SOUROUR, D. A. How to protect doxorubicin-induced cardiomyopathy in male albino rats? Journal of cardiovascular pharmacology, v. 55, n. 3, p. 262268, 2010.

SHI, Y.; MOON, M.; DAWOOD, S.; MCMANUS, B.; LIU, P. P. Mechanisms and management of doxorubicin cardiotoxicity. Herz, v. 36, n. 4, p. 296-305, 2011.

ŠIMU゚NEK, T.; ŠTĚRBA, M.; POPELOVÁ, O.; ADAMCOVÁ, M.; HRDINA, R.; GERŠI, $\mathrm{V}$. Anthracycline-induced cardiotoxicity: Overview of studies examining the roles of 
oxidative stress and free cellular iron. Pharmacological Reports, v. 61, n. 1, p. 154171, 2009.

SINGH, G.; SINGH, A. T.; ABRAHAM, A.; BHA, B.; MUKHERJEE, A.; VERMA, R.; AGARWAL, S. K.; JHA, S.; MUKHERJEE, R.; BURMAN, A. C. Protective effects of Terminalia arjuna against Doxorubicin-induced cardiotoxicity. Journal of Ethnopharmacology, v. 117, n. 1, p. 123-129, 2008.

SLEEPER, M. M.; BUCHANAN, J. W. Vertebral scale system to measure heart size in growing puppies. Journal of the American Veterinary Medical Association, v. 219 , n. 1, p. 57-59, 2001.

SPINALE, F. G.; COKER, M. L.; HEUNG, L. J.; BOND, B. R.; GUNASINGHE, H. R.; ETOH, T.; GOLDERG, A. T.; ZELLNER, J. L.; CRUMBLEY, A. J. A matrix metalloproteinase induction/activation system exists in the human left ventricular myocardium and is upregulated in heart failure. Circulation, v. 102, n. 16, p. 19441949, 2000.

ŠTĚRBA, M.; POPELOVÁ, O.; VÁVROVÁ, A.; JIRKOVSKÝ, E.; KOVAŘÍKOVÁ, P.; GERŠL, V.; ŠIMŮNEK, T. Oxidative Stress, Redox Signaling, and Metal Chelation in Anthracycline Cardiotoxicity and Pharmacological Cardioprotection. Antioxidants \& Redox Signaling, v. 18, n. 8, p. 899-929, 2012.

THOMAS, C. V; COKER, M. L.; ZELLNER, J. L.; HANDY, J. R.; CRUMBLEY, A. J.; SPINALE, F. G. Increased matrix metalloproteinase activity and selective upregulation in LV myocardium from patients with end-stage dilated cardiomyopathy. Circulation, v. 97, n. 17, p. 1708-1715, 1998.

THRALL, M. A.; WEISER, G.; ALLISON, R. W.; CAMPBELL, T. W. Hematologia e bioquímica clínica veterinária. $2^{a}$. ed. São Paulo, SP: Roca, 2015.

TSAI, H. R.; GJESDAL, O.; WETHAL, T.; HAUGAA, K. H.; FOSS, A.; FOSS, S. D.; EDVARDSEN, T. Left ventricular function assessed by two-dimensional speckle tracking echocardiography in long-term survivors of hodgkin's lymphoma treated by mediastinal radiotherapy with or without anthracycline therapy. American Journal of Cardiology, v. 107, n. 3, p. 472-477, 2011.

VISSE, R.; NAGASE, $H$. Matrix metalloproteinases and tissue inhibitors of metalloproteinases: Structure, function, and biochemistry. Circulation Research, v. 92, p. 827-839, 2003.

VOGELSANG, T. W.; JENSEN, R. J.; HESSE, B.; KJAER, A. BNP cannot replace gated equilibrium radionuclide ventriculography in monitoring of anthracyclineinduced cardiotoxity. International Journal of Cardiology, v. 124, n. 2, p. 193-197, 2008.

WALKER, C. M.; SALDANA, D. A.; GLADISH, G. W.; DICKS, D. L.; KICSKA, G.; MITSUMORI, L. M.; REDDY, G. P. Cardiac complications of oncologic therapy. RadioGraphics, v. 33, n. 6, p. 1801-1815, 2013. 
WALKER, J. R.; SHARMA, A.; LYTWYN, M.; BOHONIS, S.; THLIVERIS, J.; SINGAL, P. K.; JASSAL, D. S. The cardioprotective role of probucol against anthracycline and trastuzumab-mediated cardiotoxicity. Journal of the American Society of Echocardiography, v. 24, n. 6, p. 699-705, 2011.

WANG, Y.; WANG, S.; GAO, Y. S.; CHEN, Z.; ZHOU, H. M.; YAN, Y. B. Dissimilarity in the Folding of Human Cytosolic Creatine Kinase Isoenzymes. PLoS ONE, v. 6, n. 9, p. e24681, 9 set. 2011.

WILLIAMSON, M. A.; SNYDER, L. M. Wallach - Interpretação de exames laboratoriais. 9a . ed. Rio de Janeiro, RJ: Guanabara-Koogan, 2013.

XIN, Y. F.; WAN, L. L.; PENG, J. L.; GUO, C. Alleviation of the acute doxorubicininduced cardiotoxicity by Lycium barbarum polysaccharides through the suppression of oxidative stress. Food and Chemical Toxicology, v. 49, n. 1, p. 259-264, 2011.

YANCY, C. W. et al. 2013 ACCF/AHA guideline for the management of heart failure: A report of the american college of cardiology foundation/american heart association task force on practice guidelines. Circulation, v. 128, n. 16, 2013.

YANG, F.; TEVES, S. S.; KEMP, C. J.; HENIKOFF, S. Doxorubicin, DNA torsion, and chromatin dynamics. Biochimica et Biophysica Acta - Reviews on Cancer, v. 1845, n. 1, p. 84-89, 2014.

YEH, J. M.; NOHRIA, A.; DILLER, L. Routine echocardiography screening for asymptomatic left ventricular dysfunction in childhood cancer survivors: A modelbased estimation of the clinical and economic effects. Annals of Internal Medicine, v. 160 , n. 10, p. 661-671, 2014.

ZHAO, W. J.; WEI, S. N.; ZENG, X. J.; XIA, Y. L.; DU, J.; LI, H. H. Gene expression profiling identifies the novel role of immunoproteasome in doxorubicin-induced cardiotoxicity. Toxicology, v. 333, p. 76-88, 2015.

ZHENG, W.; WANG, S. Y. Antioxidant activity and phenolic compounds in selected herbs. Journal of Agricultural and Food Chemistry, v. 49, n. 11, p. 5165-5170, 2001.

ZHENG, J.; LEE, H. C. M.; SATTAR, M. M. B.; HUANG, Y.; BIAN, J. S. Cardioprotective effects of epigallocatechin-3-gallate against doxorubicin-induced cardiomyocyte injury. European Journal of Pharmacology, v. 652, n. 1-3, p. 82-88, 2011. 